\title{
Effects of Glucose Concentration on Biomass, Maximum Specific Growth Rate and Extracellular Enzyme Production by Three Species of Cutaneous Propionibacteria Grown in Continuous Culture
}

\author{
By J. GREENMAN, ${ }^{1}$ K. T. HOLLAND ${ }^{1 *}$ AND W. J. CUNLIFFE ${ }^{2}$ \\ ${ }^{1}$ Department of Microbiology, University of Leeds, Leeds LS2 95J, U.K. \\ ${ }^{2}$ Department of Dermatology, The General Infirmary and St. James' (University) Hospital, \\ Leeds LS1 3EX, U.K.
}

(Received 23 January 1981; revised 4 May 1981)

Three cutaneous propionibacteria - Propionibacterium acnes, $P$. avidum and $P$. granulosum - were grown in chemostats using semi-synthetic medium with various concentrations of glucose. Biomass rose with increasing glucose concentration up to $0.3-0.4 \%(w / v)$ and then remained constant. Propionibacterium granulosum had both a low yield and low $\mu_{\max }$ when grown in the absence of glucose suggesting that this organism is essentially 'saccharolytic' in its nutrition. In contrast, $P$. acnes and $P$. avidum had higher growth yields than $P$. granulosum and showed their highest $\mu_{\max }$ values in the absence of glucose. Extracellular lipase, hyaluronidase (hyaluronate lyase) and acid phosphatase activities varied with different glucose concentrations, but in all cases were lowest at the highest glucose concentration tested $(0.5 \%, w / v)$.

\section{INTRODUCTION}

There are three described species of cutaneous propionibacteria - Propionibacterium acnes, $P$. avidum and $P$. granulosum (Johnson \& Cummins, 1972). These three species produce a variety of extracellular enzymes including lipase (Hassing, 1971; Kellum et al., 1970; Ingham et al., 1981), hyaluronidase (hyaluronate lyase) (Puhvel \& Reisner, 1972; Ingham et al., 1979), protease, DNAase (Marples \& McGinley, 1974) and acid phosphatase (Greenman et al., 1979; Ingham et al., 1980). These substances may be important in the initiation of inflammation in acne (Holland et al., 1978).

It has been shown previously that changes in both oxygen tension and $\mathrm{pH}$ can affect the biomass and extracellular enzyme production of $P$. acnes grown in batch culture using complex medium (Holland et al., 1978). Batch culture studies using synthetic medium have shown that the nature of the carbon/energy source can also affect the biomass and extracellular enzymes of the cutaneous propionibacteria (Holland et al., 1979).

The aim of the present comparative investigation was to determine the effect of changing the concentration of glucose on the physiology of $P$. acnes, $P$. avidum and $P$. granulosum grown in chemostat cultures; extracellular enzyme production was of particular interest.

\section{METHODS}

Organisms and media. Propionibacterium acnes [laboratory strain P37l, P. avidum [laboratory strain PF77(1)] and $P$. granulosum [laboratory strain PF208(11)] (note that this strain wrongly appears as $P$. avidum in Table 1 of Holland et al., 1979) were isolated from patients attending the Dermatology Clinic at Leeds General Infirmary, and were typed according to the scheme of Marples \& McGinley (1974). The strains were maintained at $-196^{\circ} \mathrm{C}$ under liquid nitrogen. The growth medium was that used by Eaves et al. (1979) without thiamin. Sterile glucose solution $(10 \%, \mathrm{w} / \mathrm{v})$ was added aseptically to the sterile bulk medium to give the final concentration required. 
Continuous culture apparatus and conditions. Organisms were grown in a 1 litre culture vessel with control modules for temperature. pH. gas flow and stirrer rate (Series 500. L.H. Engineering. Stoke Poges, Bucks. U.K.). The growth conditions were those used by Eaves et al. (1979). The dilution rate was maintained at $0.012 \mathrm{~h}^{-1}$ for $P$. granulosum. at $0.040 \mathrm{~h}^{-1}$ for $P$. acnes and at $0.053 \mathrm{~h}^{-1}$ for $P$. acidum. These rates were chosen because of the different maximum specific growth rates of the three species. Samples were taken at regular intervals for microscopical examination and plating on RCM medium (Oxoid), which was incubated anaerobically in $\mathrm{H}_{2} / \mathrm{CO}_{2}$ $(95: 5, \mathrm{v} / \mathrm{v})$ at $37^{\circ} \mathrm{C}$ for $5 \mathrm{~d}$, and on $5 \%(\mathrm{w} / \mathrm{v})$ heated horse blood agar (Oxoid), which was incubated aerobically for $2 \mathrm{~d}$ at $37^{\circ} \mathrm{C}$, to test for purity.

Determination of biomass and maximum specific growth rates. Bacterial dry weight was used as a measure of the biomass. Cells were deposited by negative pressure filtration on to pre-dried and pre-weighed cellulose acetate filters $(25 \mathrm{~mm}$ diam.. $0.45 \mu \mathrm{m}$ porosity; Oxoid). The filters were then dried for $30 \mathrm{~min}$ under an infrared lamp, cooled to room temperature and re-weighed. The bacterial dry weight was obtained from the difference in the weights.

The maximum specific growth rate $\left(\mu_{\max }\right)$ was determined by the 'washout method' of Tempest (1970) by plotting the dry weight against time and calculating $\mu_{\max }$ from the slope of the curve. making use of the equation: $\ln \left(N_{1}: N_{0}\right)=\left(\mu_{\max }-D\right)\left(t_{1}-t_{0}\right)$. where $D$ is the dilution rate above $\mu_{\max }$, and $N_{0}$ and $N_{1}$ are bacterial concentrations (as measured by dry weight) at times $t_{0}$ and $t_{1}$. respectively, during the washout phase of the culture. The dilution rate was raised to near $\mu_{\max } 48 \mathrm{~h}$ before it was raised above $\mu_{\max }$. The values of $D$ above $\mu_{\max }$ were $0 \cdot 30$. 0.28 and $0.29 \mathrm{~h}^{-1}$ for P. acnes, 0.34, 0.36 and $0.32 \mathrm{~h}^{-1}$ for $P$. avidum, and $0.24,0.28$ and $0.28 \mathrm{~h}^{-1}$ for $P$. granulosum, at glucose concentrations of 0.0 .2 and $0.5 \%(\mathrm{w} / \mathrm{v})$, respectively.

Extracellular enzymes. Lipase (EC 3.1.1.3), hyaluronidase (EC 4.2.99.1) and acid phosphatase (EC 3.1.3.2) activities were assayed by the methods used by Holland et al. (1979). All activities were expressed as $\mu \mathrm{mol}$ end-product $\mathrm{h}^{-1}$ ( $\mathrm{mg}$ dry wt cells) $)^{-1}$.

Glucose. Glucose in the medium was assayed by the method of Huggett \& Nixon (1957).

Phosphorus. Total phosphorus in the medium was determined by the method described in the Ministry of Agriculture. Fisheries and Food (1973) Technical Bulletin 27; phosphates were determined according to Chen et al. (1956).

Steady state. Biomass and extracellular enzyme activities were determined on samples taken from the chemostat during the particular conditions of nutrition that were selected. Only after a minimum of six culture volume changes had occurred between particular conditions was a steady-state condition considered to have been achieved.

\section{RESULTS}

Cell biomass and extracellular enzyme production were measured for each species of Propionibacterium grown at steady state, with the glucose concentration in the growth medium increased from 0 to $0.5 \%(w / v)$ in $0.1 \%(w / v)$ increments.

\section{Biomass}

The biomass increased until the glucose concentration reached $0.3 \%(\mathrm{w} / \mathrm{v})$ for $P$. avidum and $P$. granulosum and $0.4 \%(\mathrm{w} / \mathrm{v})$ for $P$. acnes. Biomass then remained constant or decreased slightly with further increases in the glucose concentration (Fig. 1). Under 'no glucose' conditions, $P$. acnes and $P$. avidum had approximately fourfold higher initial yields than did $P$. granulosum. At glucose concentrations between 0 and $0.3 \%(w / v)$ (Fig. 1) $P$. avidum and $P$. granulosum showed a greater increase in biomass $\left(0.27 \mathrm{~g}^{-1}\right)$ than did the $P$. acnes strain $\left(0 \cdot 11 \mathrm{~g}^{-1}\right)$.

\section{Extracellular enzyme production}

Lipase activity of $P$. acnes increased with increasing glucose concentration up to $0.3 \%$ $(w / v)$. At this point the lipase specific activity was twice that under 'no glucose' conditions. At higher glucose concentrations the activity decreased (Fig. 2). For $P$. avidum, the lipase activity remained almost unchanged up to $0.3 \%(\mathrm{w} / \mathrm{v})$ glucose, was higher with $0.4 \%(\mathrm{w} / \mathrm{v})$ glucose, but fell again when the concentration was increased to $0.5 \%(\mathrm{w} / \mathrm{v})$. Lipase activity of $P$. granulosum was very high when the cells were grown without glucose. This activity decreased when the cells were grown on $0.1 \%(w / v)$ glucose, remained nearly constant up to 


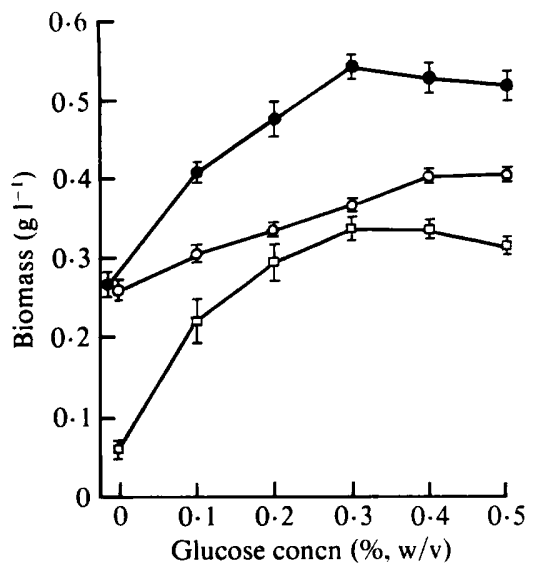

Fig. 1

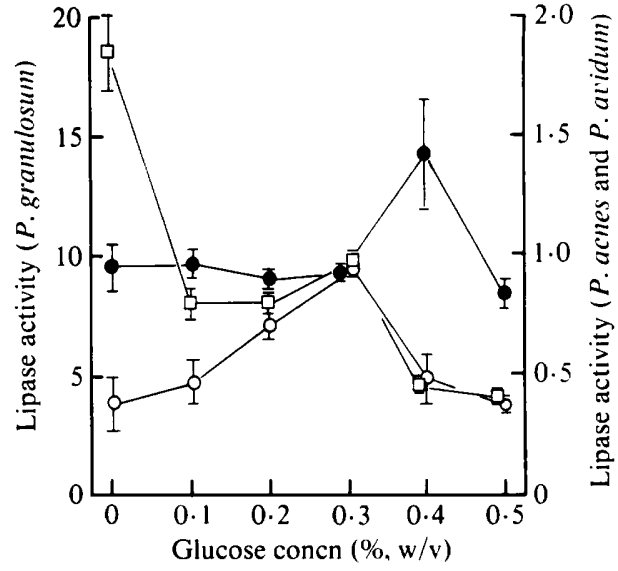

Fig. 2

Fig. 1. Effect of glucose concentration on the biomass of $P$. acnes $(O)\left(D=0.04 \mathrm{~h}^{-1}\right), P$. avidum (O) $\left(D=0.05 \mathrm{~h}^{-1}\right)$ and $P$. granulosum $(\square)\left(D=0.01 \mathrm{~h}^{-1}\right)$. Each point and bar indicates the mean \pm standard deviation for nine separate samples.

Fig. 2. Effect of glucose concentration on the production of lipase by $P$. acnes $(O), P$. avidum $(O)$ and $P$. granulosum $(\square)$. Lipase activities are expressed as $\mu$ mol oleic acid released $\mathrm{h}^{-1}\left(\mathrm{mg}\right.$ dry wt cells) ${ }^{-1}$. Other details as for Fig. 1.

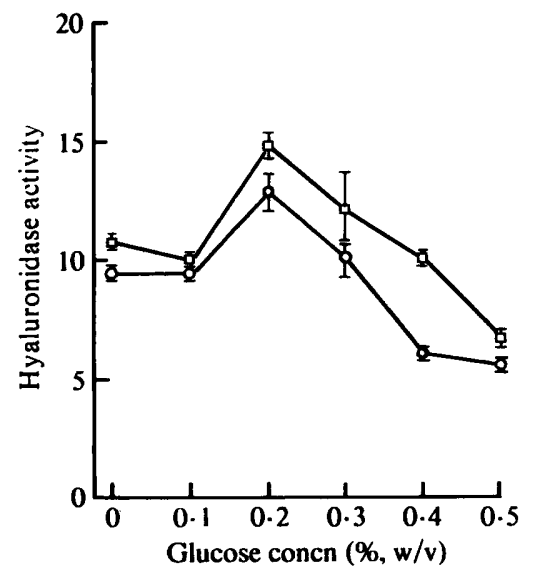

Fig. 3

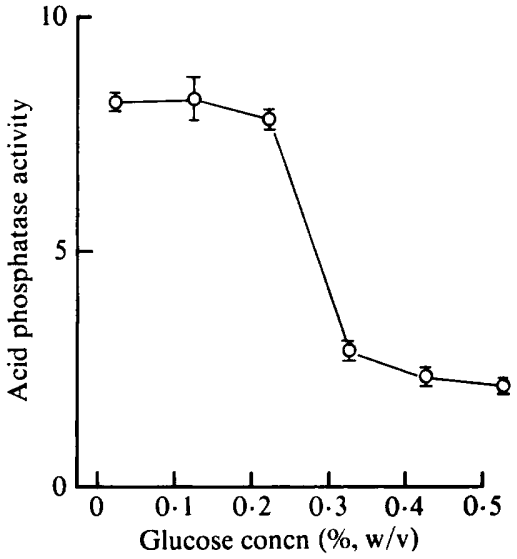

Fig. 4

Fig. 3. Effect of glucose concentration on the production of hyaluronidase by $P$. acnes $(O)$ and $P$. granulosum ( $\square$ ). Hyaluronidase activites are expressed as $\mu \mathrm{mol} N$-acetylglucosamine released $\mathrm{h}^{-1}(\mathrm{mg}$ dry wt cells) $)^{-1}$. Other details as for Fig. 1.

Fig. 4. Effect of glucose concentration on the production of acid phosphatase by $P$. acnes $(O)$. Acid phosphatase activities are expressed as $\mu \mathrm{mol} p$-nitrophenol released $\mathrm{h}^{-1}$ ( $\mathrm{mg}$ dry wt cells) ${ }^{-1}$. Other details as for Fig. 1.

$0.3 \%(w / v)$ glucose, and finally decreased again at higher glucose concentrations to about a quarter of that in the absence of glucose.

Hyaluronidase was produced only by the $P$. acnes and $P$. granulosum strains (Fig. 3). The pattern of production for these two strains was similar. Specific activity was about $50 \%$ higher with $0.2 \%(\mathrm{w} / \mathrm{v})$ glucose than without glucose. As the concentration was progressively increased above $0.2 \%(\mathrm{w} / \mathrm{v})$, hyaluronidase activity steadily decreased. 
Table 1. Effect of glucose concentration on the maximum specific growth rate of $P$. acnes, $P$. avidum and $P$. granulosum

$\begin{array}{lcc}\text { Species } & \begin{array}{c}\text { Glucose concn } \\ (\%, w / v)\end{array} & \begin{array}{c}\mu_{\max } \\ \left(\mathrm{h}^{-1}\right)\end{array} \\ \text { P. acnes } & 0 & 0.16 \\ & 0.2 & 0.09 \\ \text { P. avidum } & 0.5 & 0.09 \\ & 0 & 0.18 \\ \text { P. granulosum } & 0.2 & 0.08 \\ & 0.5 & 0.10 \\ & 0 & 0.02 \\ & 0.2 & 0.06 \\ & 0.5 & 0.03\end{array}$

Extracellular acid phosphatase was detected only in the $P$. acnes strain (Fig. 4). The enzyme specific activity was the same with $0,0.1$ or $0.2 \%(\mathrm{w} / \mathrm{v})$ glucose in the growth medium. With $0.3 \%(\mathrm{w} / \mathrm{v})$ glucose and above, activity was much lower (about one-third of that in the absence of glucose).

\section{Maximum specific growth rates}

Values of $\mu_{\max }$ obtained by the 'washout method' are shown in Table 1 . The $P$. acnes and $P$. avidum strains showed similar trends in that the highest values for $\mu_{\max }$ were obtained when they were grown without any glucose in the medium $\left(0.16\right.$ and $0.18 \mathrm{~h}^{-1}$, respectively). In contrast, $P$. granulosum showed its lowest value for $\mu_{\max }\left(0.02 \mathrm{~h}^{-1}\right)$ when grown under these conditions.

The values of $\mu_{\max }$ for $P$. acnes and $P$. avidum at 0.2 and $0.5 \%(\mathrm{w} / \mathrm{v})$ glucose were similar (between 0.08 and $0.10 \mathrm{~h}^{-1}$ ) and were approximately half that of the $\mu_{\max }$ in the 'no glucose' environment. In contrast, the $\mu_{\max }$ of $P$. granulosum was about three times higher in the presence of $0.2 \%(\mathrm{w} / \mathrm{v})$ glucose $\left(0.6 \mathrm{~h}^{-1}\right)$ than in its absence. With $0.5 \%(\mathrm{w} / \mathrm{v})$ glucose, $\mu_{\max }$ was again low (though not as low as in the absence of glucose).

\section{DISCUSSION}

Ideally, experiments comparing specific growth rates, biomass and extracellular enzyme production should be performed with carbon-limiting and nitrogen-limiting conditions. However, as $P$. acnes, $P$. avidum and, to some extent, $P$. granulosum can utilize amino acids as carbon/energy as well as nitrogen sources, and as the nutritional requirements are complex (Ferguson \& Cummins, 1978; Holland et al., 1979), simple carbon-limiting conditions using glucose alone could not be obtained. Therefore, the experiments to determine $\mu_{\max }$ were conducted using the following three conditions: no glucose, $0.2 \%(\mathrm{w} / \mathrm{v})$ glucose and excess glucose. Glucose at $0.2 \%(\mathrm{w} / \mathrm{v})$ probably represents carbon/energy limitation, because the addition of more glucose resulted in a higher biomass and less than $1 \mu \mathrm{g}$ glucose $\mathrm{ml}^{-1}$ was detected in the cultures. Although the growth limitation in media with $0.5 \%(w / v)$ glucose could not be defined, phosphate was not limiting in these experiments.

Incremental yields of $P$. acnes with increasing glucose concentrations were smaller than those of $P$. avidum and $P$. granulosum indicating a more efficient use of glucose by the latter two species.

The $P$. granulosum strain showed differences to the $P$. acnes and $P$. avidum strains used in this study. Its $\mu_{\max }$ was lowest and it had a very low biomass when grown under 'no glucose' conditions. This result is in agreement with an earlier report (Holland et al., 1979) that $P$. granulosum failed to grow in a synthetic medium containing a high concentration of arginine but grew in the same medium with a low arginine concentration; neither medium contained 
glucose. At low arginine concentrations the biomass was similar to that obtained in the present study using 'no glucose' tryptone medium. However, with $P$. acnes and $P$. avidum the biomass was lower in the synthetic medium than in tryptone medium. This effect may be due to the differences in the culturing systems and the lack of peptides in the synthetic medium. The metabolism of $\boldsymbol{P}$. granulosum is basically 'saccharolytic' and it is unable to utilize amino acids or small peptides efficiently as carbon/energy sources. It is possible that in the protein-rich skin environment $P$. acnes and $P$. avidum rely on proteinases (Marples \& McGinley, 1974) to scavenge for amino acids and peptides as a carbon/energy source, whereas the non-proteolytic $P$. granulosum is dependent on other carbon/energy sources.

Under the conditions tested, $P$. acnes and $P$. avidum showed their highest $\mu_{\max }$ when grown under 'no glucose' conditions. Presumably a variety of metabolic pathways and permease transport systems are available to permit these organisms to utilize the different amino acids present in the medium. In the presence of glucose, the $\mu_{\max }$ of both $P$. acnes and P. avidum was $>40 \%$ lower than under 'no glucose' conditions. This might be explained by glucose repression of the synthesis of enzymes important in obtaining carbon/energy from amino acids.

Of the three species tested, $P$. avidum seems the most nutritionally adaptable because it grew well in 'no glucose' conditions and responded to glucose addition with a greater increase in biomass than the other two species. However, on the skin P. acnes is the most commonly found species, whilst $P$. avidum is restricted in habitat (McGinley et al., 1978). This would suggest that nutrient adaptability is not the major factor controlling the population of these species on human skin.

Extracellular enzymes may function to supply the organisms with carbon/energy sources in vivo. Lipase could provide the organisms with a source of glycerol, which they are known to be able to utilize (Holland et al., 1979), from triglycerides found in sebum (Rebello \& Hawk, 1978), although triglyceride would not be a very efficient substrate for providing the organisms with energy.

Lipase production by $P$. granulosum (Fig. 2) was highest when the cells were grown without glucose and this production was reduced by the presence of glucose $(0 \cdot 1 \%, w / v)$, suggesting repression of lipase synthesis. The effect of glucose on lipase production by $P$. acnes and $P$. avidum was opposite to that of $P$. granulosum, in that they showed increases in lipase activity with the addition of glucose. The control over lipase production in $P$. acnes and $P$. avidum in response to changes in glucose concentration seems to be weak, with maximum changes of twofold or less compared with a fourfold change for P. granulosum. The different response of $P$. granulosum might be explained by its greater dependence on fermentable substrates, and for this species greater control over lipase production would be an advantage. The other two species would benefit little from such control. It is notable that $P$. granulosum produced 20 times more lipase per unit biomass than either $P$. acnes or $P$. avidum.

Extracellular enzyme activities were lowest when glucose was at its highest concentration $(0.5 \%, \mathrm{w} / \mathrm{v})$. This trend might indicate that so-called catabolite repression (Magasanik, 1961 ) is occurring, whereby a freely available carbon/energy source represses the synthesis of enzymes now redundant since they are concerned with acquiring more carbon/energy. This type of repression also allows conservation of nitrogen needed for more important cellular functions in the, possibly, nitrogen-limited conditions. However, more drastic reduction in extracellular enzyme production by low concentrations of glucose would be expected if this was the control mechanism. Only with the acid phosphatase of $P$. acnes and the lipase of $P$. granulosum does this type of repression seem to occur and even then it is not complete.

This study suggests that physiological responses in $P$. granulosum differ from those of $P$. acnes and $P$. avidum, and $P$. granulosum may rely on different mechanisms to $P$. acnes and $P$. avidum to survive on the skin. Until more information is available on the microenvironment of the skin, the physiology of the bacteria living there will remain a matter of conjecture. 
The authors wish to acknowledge the financial support of the Medical Research Council throughout this study.

\section{REFERENCES}

Chen, P. S., Toribara, T. Y. \& Warner, H. (1956). Microdetermination of phosphorus. Analytical Chemistry 28, 1756-1758.

Eaves, G., Greenman, J. \& Holland, K. T. (1979) Decay rates of exocellular enzymes produced by bacteria - correction of production rates in chemostat cultures. FEMS Microbiology Letters 6, 333336.

Ferguson, D. A. \& Cummins. C. S. (1978). Nutritional requirements of anaerobic coryneforms. Journal of Bacteriology 135, 858-867.

Greenman, J.. Cunliffe, W. J. \& Holland, K. T. (1979). The effect of nutritional changes on production of exocellular, biologically active substances by Propionibacterium acnes grown on a synthetic medium. Journal of Investigative Dermatology 70 , 228 (abstract).

Hassing, G. S. (1971). Partial purification and some properties of lipase from Corynebacterium acnes. Biochimica et biophysica acta 242, 381-394.

Holland, K. T., CunlffFe, W. J. \& Roberts, C. D. (1978). The role of bacteria in acne - a new approach. Clinical and Experimental Dermatology 3. 253-257.

Holland, K. T., Greenman. J. \& Cunliffe. W. J. (1979). Growth of Propionibacterium acnes on synthetic medium: growth yields and exoenzyme production. Journal of Applied Bacteriology 47, 383-394.

Huggett, A. St.G. \& Nixon, D. A. (1957). Enzymic determination of blood glucose. Biochemical Journal 66. $\mathrm{P} 12$.

Ingham, E., Holland, K. T., Gowland, G. \& Cunliffe, W. J. (1979). Purification and partial characterization of hyaluronate lyase (EC 4.2.99.1) from Propionibacterium acnes. Journal of General Microbiology 115, 411-418.

Ingham, E., Holland, K. T., Gowland, G. \& Cunliffe, W. J. (1980). Purification and partial characterization of an acid phosphatase (EC
3.1.3.2) produced by Propionibacterium acnes. Journal of General Microbiology 118, 59-65.

Ingham, E., Holland, K. T., Gowland, G. \& Cunliffe, W. J. (1981). Partial purification and characterization of lipase (EC 3.1.1.3) from Propionibacterium acnes. Journal of General Microbiology 124, 393-401.

Johnson, J. L. \& Cummins, C. S. (1972). Cell wall composition and deoxyribonucleic acid similarities among the anaerobic coryneforms, classical propionibacteria, and strains of Arachnia propionica. Journal of Bacteriology 109, 1047-1066.

Kellum, R. E., Strangfeld, K. \& RAY, L. F. (1970). Acne vulgaris. Studies in pathogenesis: triglyceride hydrolysis by Corynebacterium acnes in vitro. Archives of Dermatology 101, 41-47.

MAgasanik, B. (1961). Cellular regularity mechanisms. Cold Spring Harbor Symposia on Quantitative Biology 26, 249-256.

Marples, R. R. \& McGinley, K. J. (1974). Corynebacterium acnes and other anaerobic diphtheroids from human skin. Journal of Medical Microbiology 7, 349-357.

McGinley, K. J., Webster, G. F. \& Leyden, J. J. (1978). Regional variations of cutaneous propionibacteria. Applied and Environmental Microbiology 35, 62-66.

Ministry of Agriculture, Fisheries and Food (1973). The Analysis of Agricultural Material. Technical Bulletin 27. London: HMSO.

Punvel, S. M. \& Reisner, R. M. (1972). The production of hyaluronidase (hyaluronate lyase) by Corynebacterium acnes. Journal of Investigative Dermatology 58, 66-70.

Rebello, T. \& HaWk, J. L. M. (1978). Skin surface glycerol levels in acne vulgaris. Journal of Investigative Dermatology 70, 352-354.

TEMPEST, D. W. (1970). The continuous cultivation of micro-organisms. 1. Theory of the chemostat. Methods in Microbiology 2, 259-276. 